\title{
Enhancing Engineers' Contributions to Global Society
}

\author{
Arani Kajenthira \\ Social Change Fellow \\ Curriculum Enhancement \\ Engineers Without Borders (Canada) \\ aranikajenthira@ewb.ca
}

\author{
Jonathan M. Fishbein \\ Director, Curriculum Enhancement and \\ Global Engineering \\ Engineers Without Borders (Canada) \\ jonathanfishbein@ewb.ca
}

\begin{abstract}
Engineering is often perceived as a technology-driven profession, rather than one that is capable of successfully applying scientific principles to address key societal challenges. Over the past five years, Engineers Without Borders (Canada) (hereafter, EWB) has been working in collaboration with engineering faculties across Canada to address the acknowledged weaknesses in engineering graduates by focusing on developing "Global Engineers": engineers with the breadth of thinking necessary to tackle the world's most complex problems. This paper outlines EWB's Global Engineering concept, which was developed in consultation with engineering students, professors, and practitioners, and links to existing definitions of Global Engineering, to emerging trends in engineering practice and to the continually evolving needs of industry. A four-year curriculum enhancement framework is also introduced as a potential means of encouraging broader thinking in engineering undergraduates. EWB's framework outlines a learning progression that can be incorporated into any engineering discipline, and allows for the integration of curriculum resources that encourage outside-the-box thinking and the development of nuanced problem-solving abilities. Finally, this paper will present our best practices in two case studies that clearly illustrate EWB's approach to curriculum enhancement. By fusing both technical and non-technical concepts, allowing them to be taught in parallel in a single class, our resources intellectually engage both technically-driven and socially-minded students, and are carefully structured to aid faculty members in classroom delivery.
\end{abstract}

\section{Introduction}

The perception of engineering as a primarily technology-driven profession [1] undermines its potential as a vocation that is capable of applying scientific principles to solve problems for the benefit of society [2-4]. As a result of these preconceived notions, engineering programs tend to attract students that are interested in mathematics, science and technology, and are based on an engineering curriculum that focuses on proficiency in the mathematics and sciences. This ultimately creates engineers that have strengthened their core competencies while successfully avoiding their weaknesses, e.g. communication skills, cultural understanding, and economics [5].

The new outcomes-based accreditation process being implemented by the Canadian Engineering Accreditation Board (CEAB) pressures the curriculum to expand beyond its traditional boundaries and shifts towards a societal focus, with an emphasis on communication skills, professionalism, and a commitment to life-long learning [6]. Engineers Without Borders (Canada) (hereafter, EWB) views this transition to an outcomes-based accreditation system as an ideal opportunity to address acknowledged weaknesses in the engineering profession and to create Global Engineers: engineers that are capable of broader thinking and are better equipped to tackle the highly nuanced, complex problems that are commonplace in present-day society [5]. This paper presents EWB's vision of a four-year program that could augment the existing engineering curriculum by integrating carefully designed resources that facilitate the creation of Global Engineers.

\section{Context for Change}

It is undeniable that the problems faced by engineers in society are evolving as a result of globalization and the increase in significant and critical global issues (e.g. global warming, extreme poverty, and the rising cost of health care). Although these issues are by no means novel, their increasing scope, magnitude and complexity require more innovative responses. Both the engineering profession 
and individual engineers must evolve to meet these challenges, a necessity that has been recognized by the shift in the CEAB accreditation philosophy. Rather than an exclusive focus on the class hours comprising engineering programs, the CEAB now seeks to investigate the competencies of engineering undergraduates to determine if they possess the desired attributes upon graduation [6]. These new outcomes also emphasize the importance of graduating engineers understanding their role in society by increasing the emphasis on professional ethics, accountability and equity [7], and addressing known concerns about the lack of communication and teamwork skills [8].

EWB's concept of Global Engineers, partly defined by our experience with highly complex problems in developing communities, leverages the particular expertise of our organization in enhancing the desired competencies of graduating engineering students.

\section{The Concept of Global Engineering}

Global Engineers have been broadly defined by academic and non-governmental organizations alike [9], but are characterized by EWB Canada as: engineers that possess the knowledge, skills and attributes to play a direct role in creating social change, be it through government, corporations, or non-governmental organizations. Ideally, the sociallyresponsible decision-making of these individuals will gradually result in an engineering profession that is more service oriented, with an understanding of the cross-disciplinary, business and social implications of their work. Global Engineers have been distinguished more explicitly as being in possession of nine desirable attributes (Table 1) [5,9].

Although some of these desirable attributes are implicit in the current engineering curriculum, the vast majority of the necessary skills are not effectively integrated into and/or implemented by the traditional education system, which favours mutually exclusive information delivery rather than the parallel teaching of technical and social concepts. Consequently, a sufficient understanding of the organizational, economic and environmental issues that frequently impact the engineering process is often lacking in engineering graduates.

EWB recognizes that the growth and development of potential Global Engineers will involve multiple formative influences, including their peer groups, personal values, and work experiences. However, we also believe that there is a unique and substantial opportunity to shape the hearts and minds of future engineers by enriching their formal education.
Table 1. Attributes of Global Engineers

\begin{tabular}{|c|c|}
\hline 1 & $\begin{array}{l}\text { Have a good understanding of engineering } \\
\text { principles, theories, standards, and techniques }\end{array}$ \\
\hline 1 & $\begin{array}{l}\text { Appreciate the broader, 'big-picture' context of } \\
\text { engineering practice, recognizing the } \\
\text { importance of cross-disciplinary, social and } \\
\text { economic aspects }\end{array}$ \\
\hline 2 & $\begin{array}{l}\text { Possess engineering expertise in a specific } \\
\text { discipline, but are comfortable working in an } \\
\text { interdisciplinary manner across multiple areas }\end{array}$ \\
\hline 3 & $\begin{array}{l}\text { Are creative, outside-the-box problem-solvers } \\
\text { that can adapt to new, complex situations and } \\
\text { are skilled at systems thinking }\end{array}$ \\
\hline 4 & $\begin{array}{l}\text { Possess knowledge and/or understanding of } \\
\text { diverse cultures and communities and are able } \\
\text { to apply collaboration techniques. }\end{array}$ \\
\hline 5 & $\begin{array}{l}\text { Can communicate clearly, both verbally and in } \\
\text { writing, to a variety of audiences and across } \\
\text { language, social, economic and/or cultural } \\
\text { barriers. }\end{array}$ \\
\hline 6 & $\begin{array}{l}\text { Recognize the importance of sustainability and } \\
\text { have a well-developed sense of social } \\
\text { responsibility and ethics, with due } \\
\text { consideration of the world and society in both } \\
\text { their personal and professional lives }\end{array}$ \\
\hline 7 & $\begin{array}{l}\text { Substantial knowledge of current world issues } \\
\text { and emerging trends, while continually } \\
\text { expanding their skills to be able to respond to } \\
\text { these issues appropriately }\end{array}$ \\
\hline 9 & $\begin{array}{l}\text { Possess an entrepreneurial spirit, the ability to } \\
\text { work with varying levels of resources and to } \\
\text { take on diverse roles in different organizations } \\
\text { and professional settings. }\end{array}$ \\
\hline
\end{tabular}

\subsection{A Program of Integrative Enhancement}

To affect the development of Global Engineers through formal education, three obvious opportunities have been cited within the present educational curriculum: integrative enhancement, interdisciplinary options, and complementary studies electives [5]. The current proposal is a four-year program of integrative enhancement that integrates Bloom's Taxonomy of learning objectives [10] and collectively edifies both technical and social concepts (Table 2). 
Table 2. Proposed Four Year Program of Integrative Enhancement

\begin{tabular}{|c|c|c|}
\hline YEAR I & \multicolumn{2}{|c|}{ KNOWLEDGE $\Rightarrow$ COMPREHENSION } \\
\hline $\begin{array}{l}\text { Learning } \\
\text { Objective }\end{array}$ & \multicolumn{2}{|c|}{$\begin{array}{l}\text { To develop students' knowledge of global realities and societal challenges, increasing overall } \\
\text { comprehension of and enhancing opportunities to reflect upon both Canadian and global issues. }\end{array}$} \\
\hline $\begin{array}{l}\text { Potential } \\
\text { Topics }\end{array}$ & $\begin{array}{l}\text { Agriculture and Food Security } \\
\text { Aid and Debt } \\
\text { Environment and Climate Change } \\
\text { Gender }\end{array}$ & $\begin{array}{l}\text { Information and Communication Technologies } \\
\text { Millennium Development Goals } \\
\text { Migration } \\
\text { Water and Sanitation }\end{array}$ \\
\hline YEAR II & \multicolumn{2}{|c|}{ COMPREHENSION $\Rightarrow$ APPLICATION } \\
\hline $\begin{array}{l}\text { Learning } \\
\text { Objective }\end{array}$ & \multicolumn{2}{|c|}{$\begin{array}{l}\text { A heightened understanding of local and global actors, institutions and challenges, with the ability } \\
\text { to analyze and reflect upon previous and current mitigation strategies and to recognize the } \\
\text { potential role of engineers in addressing these issues. }\end{array}$} \\
\hline $\begin{array}{l}\text { Potential } \\
\text { Topics }\end{array}$ & $\begin{array}{l}\text { Conflict, Emergencies and Rebuilding } \\
\text { Education, Children and Youth } \\
\text { Finance and Economics } \\
\text { Health }\end{array}$ & $\begin{array}{l}\text { Poverty } \\
\text { Rights and Social Protection } \\
\text { Social Equality } \\
\text { Trade }\end{array}$ \\
\hline YEAR III & \multicolumn{2}{|l|}{ APPLICATION $\Leftrightarrow$ ANALYSIS } \\
\hline $\begin{array}{l}\text { Learning } \\
\text { Objective }\end{array}$ & \multicolumn{2}{|c|}{$\begin{array}{l}\text { To enhance students' abilities to dissect and analyze existing information to create designs which } \\
\text { satisfy not only technical and economic constraints but also address social criteria in potential } \\
\text { implementation. By receiving comprehensive feedback, students will increase their analytical } \\
\text { abilities and overall awareness of societal factors that can cause the failure of even cost-effective, } \\
\text { technically proficient designs. Finally, students should also have the ability to communicate across } \\
\text { economic and cultural boundaries and should recognize their role as engineers, Canadians, and } \\
\text { global citizens. }\end{array}$} \\
\hline \multirow[t]{2}{*}{$\begin{array}{l}\text { Potential } \\
\text { Topics }\end{array}$} & $\begin{array}{l}\text { Appropriate Technology } \\
\text { Adaptive Technologies } \\
\text { Canada's role overseas }\end{array}$ & $\begin{array}{l}\text { Corporate social responsibility } \\
\text { Cross-cultural communication } \\
\text { Global citizenship }\end{array}$ \\
\hline & \multicolumn{2}{|c|}{$\begin{array}{l}\text { Previous mitigation strategies and challenges with implementation - why are desired impacts so } \\
\text { rarely achieved? } \\
\text { What is the unique skill set of an engineer? } \\
\text { As engineers, how can we create measurable impact in these societal challenges? }\end{array}$} \\
\hline Year IV & \multicolumn{2}{|c|}{ ANALYSIS $\Leftrightarrow$ SYNTHESIS $\Leftrightarrow$ EVALUATION } \\
\hline $\begin{array}{l}\text { Learning } \\
\text { Outcomes }\end{array}$ & \multicolumn{2}{|c|}{$\begin{array}{l}\text { The ability to source and analyze the relevant and necessary information to develop engineering } \\
\text { designs that satisfy technical, economic and societal constraints and criteria, while integrating the } \\
\text { necessary iterative processes to evaluate successive stages of the proposed design. }\end{array}$} \\
\hline $\begin{array}{l}\text { Potential } \\
\text { Topics }\end{array}$ & Engineering Ethics & Engineering and Sustainability \\
\hline
\end{tabular}

When examining the proposed Program, it is important to note that the curriculum incorporates a linear progression of the first three concepts in Bloom's Taxonomy in Years I - II (Knowledge,
Comprehension, Application) but incorporates the remaining concepts (Analysis, Synthesis and Evaluation) in parallel in Years III - IV. Additionally, although the majority of theoretical knowledge will be 
disseminated in the first two years, all of the topics listed will be discussed with reference to the role of the engineer and allusion to appropriate technology and sustainable design over the course of the four-year curriculum. Similarly, when Appropriate Technology, Global Citizenship, Engineering Ethics and Canada's role overseas are discussed more broadly in Years III IV, they will be discussed with reference to the topics first outlined in Years I - II, e.g. Agriculture, Water and Sanitation, and Environment and Climate Change.

By developing each of these topics and linking them more closely together through discussions of increasing complexity, it is hoped that students will develop mature, nuanced thinking about global issues that will allow them to successfully design solutions for open-ended engineering problems while also considering societal, environmental and economic issues. Additionally, students will have opportunities to implement both technical concepts and societal understanding of increasing complexity by the inclusion of case study-based learning. Finally, the emphasis of and progression from a knowledge-based foundation in Year I will allow students and faculty alike to develop a nuanced understanding of the multifaceted issues facing global society and cultivate the broader thinking necessary to accurately assess, develop, and evaluate solutions to these problems.

\subsection{Program Implementation}

The majority of engineering curriculums in Canada incorporate a course in 'Engineering Design' or 'Engineering and Society' at the first-year level; a smaller group also integrate complementary electives at this stage. To effectively enhance the societal awareness of undergraduate students within the current engineering curriculum, the first-year design course was identified as an ideal medium for initial knowledge dissemination regarding existing challenges in Canadian and international society, for the review of international organizations and governance mechanisms, and for the discussion of their inherent complications. The topics for discussion in Year I were chosen based on an anticipated initial level of student knowledge, and the discussions surrounding these topics will provide comprehensive background information while stressing the potential role of an engineer. This broader knowledge base will prepare students more comprehensively for the scope of questions and challenges they are likely to encounter in engineering practice. Likewise, faculty members teaching the Engineering Design course will improve their awareness of societal issues, increasing their ability to effectively evaluate design projects based on technical, social and economic merits.
At the second year level, students will be exposed to increasingly complex global issues through topics that expand on the ideas introduced and discussed in Year I. Again, these topics provide an opportunity for faculty members to broaden their own knowledge while facilitating discussions on these issues and identifying potential areas for engineering involvement. The concepts of appropriate and adaptive technologies, corporate social responsibility and global citizenship are also introduced, combined with discussions of Canada's role overseas and the challenges of cross-cultural communication. This stage also provides the first opportunity to integrate case study-based design projects in weekly seminars that assimilate both technical and social concepts. These case studies are necessitate the application of technical knowledge through engineering design while simultaneously advancing students' understanding of existing "solutions" to global problems by analyzing alternate strategies that failed due to social, economic or cultural reasons. The recognition that technically sound solutions can still fail at the implementation stage will prepare students to tackle more technically and socially complex design problems in Year III.

The focus of Year II is on directed engagement through application and on the analysis of multifaceted design questions that include both technical constraints and criteria as well as information on local society, government and economy. All of the necessary information required to achieve an effective design solution will be made available to the students; conceived designs will subsequently be evaluated based on students' nuanced understanding of socioeconomic challenges. At this stage, the substantial information provided will allow faculty to accurately evaluate the potential success of each design solution and provide detailed feedback to further students' understanding of latent weaknesses in their work.

The final year thesis, or capstone design project, is targeted as the definitive opportunity for students to amalgamate their technical knowledge with social understanding. Design problems at this level will be open-ended, defined either by students or their faculty supervisors, and have infinite potential solutions. However, the strong foundation provided in Years IIII will have fostered student awareness of the types of information they will require to design a viable solution, while simultaneously preparing faculty to evaluate final design solutions based on their technical, cultural and economic merits.

Crucial to the success of this program is the inclusion of opportunities for individual reflection and evaluation over the course of the four-year curriculum. The evaluation of students' perception and comprehension of critical social and technical issues 
both before and after each module will clearly illustrate changes in understanding and provide a means for appraising behavioural outcomes without substantial deviation from traditional evaluation mechanisms.

\section{Implementation and Best Practices}

Further research is needed into engineering pedagogy in order to identify best practices for implementation of the proposed integrative enhancement program. However, existing relationships between EWB Canada and Canadian engineering faculties have enabled the initial investigation of various pedagogical elements in the engineering curriculum in facilitating the development of global engineers. Through these curriculum partnerships, both peer learning and case studies have been identified as effective means of creating Global Engineers.

Peer learning, which allows students to participate in researching and presenting course material to their colleagues, has been found to raise students' levels of personal responsibility and learning involvement by creating a sense of ownership and control when approaching personal learning goals. Encouraging engineering students to research and present various curriculum areas permits them to explore and develop knowledge and skills that are not formally emphasized in the traditional curriculum, including critical thinking, communication and knowledge transfer. Such peer learning can potentially be implemented by moving from traditional lectures towards seminar-style classes, and/or by engaging senior students in teaching concepts to junior students. Involving students in elements of course delivery facilitates learning for both groups of students, simply by allowing students to build more of a connection to the material that they have previously assimilated, while providing the additional benefit of establishing both formal and informal mentor relationships.

A clear illustration of the success of peer learning is the Technology and Development (APSC 263) course at the University of British Columbia. Originally initiated as a student-directed seminar (a unique curriculum component that allows students at UBC to explore engineering-related topics of personal interest with a supporting faculty member), the course aimed to expose students to the many complex and subtle issues surrounding international development [11]. The first three weeks of the course are facilitated by trained student members of EWB Canada and covers general information on international development in addition to providing an overview of key international organizations and governance structures [11]. The remainder of the course is however facilitated by the students themselves, allowing them to present and lead discussions on five topics defined as focus areas for appropriate technology: water, food, energy, information and communication technologies (ICT) and health [11]. To effectively evaluate behavioural outcomes, students are asked to complete a basic case study on the needs of a developing community at the outset of the course. The same case study is then revisited at the conclusion of the course to assess how students' attitudes and perceptions have changed over the length of the course [11]. The consistently striking contrast between 'before' and 'after' responses clearly indicates the success of the course in altering perceptions of international development in course attendees. Additionally, in previous years, increased student participation enhanced the abilities of students to think critically and effectively, enabling them to successfully identify international development projects that were not sustainable or appropriate [11].

Incorporated alongside peer learning or independently, case studies allow students to explore and resolve real world, practical problems. Case studybased learning is particularly relevant to the development of global engineers as it allows students to gain experience with complex, open-ended and multi-disciplinary problems while simultaneously learning and applying the relevant technical concepts to resolve a specific scenario. The integration of roleplaying elements can allow students to appreciate the interpersonal and team-based challenges present in many real-world scenarios, while the definition of a specific technical problem in an international development context allows for both technical and social concepts to be taught concurrently.

EWB is developing a library of case studies that outline the unique opportunities and challenges faced by individual rural communities in Africa, and delineate specific technical challenges that can form the basis for general discussion, take-home assignments, or design projects, within a classroom setting. These case studies investigate an engineer's potential role in international projects while exposing students to the relevant technical and non-technical challenges in the local environment and providing an opportunity to shape students' mindsets through a combination of classroom discussion and the provision of substantial feedback on take-home assignments and design projects.

The relevance of combined technical and societal case studies in facilitating the development of Global Engineers was recently demonstrated by the inclusion of a water system case study in the Fluid Mechanics (MECH 2262) course at the University of Manitoba. Towards the end of the course, two successive seminar sessions were devoted to the design of a suitable water 
system for a rural community in Bolivia. In the first two-hour seminar, students were presented with minimal technical constraints and asked to work in groups to create a preliminary design based on the detailed information provided about the socioeconomic and political challenges faced by the community. The second seminar session highlighted the potential for the failure of technically competent designs by describing a technically sound yet practically unsuccessful water pump design and outlining the social and economic conditions that prevented the design from achieving its full potential upon implementation. Groups were subsequently paired together such that students could present their preliminary designs to gain feedback from their peers before making final changes and submitting both their initial and modified designs for evaluation.

From a pedagogical perspective, the changes between the initial and final designs following classroom discussion allowed for the evaluation of changes in student perspectives and understanding. Additionally, it was noted by the course facilitator that although the majority of students were intrigued by the global focus of the seminar, the inclusion of a technical design component helped engage even those members of the course less interested in international development. The case study (and its timing in the course) had been chosen because it contained technical content relevant to recent course material, i.e. head losses and the design of pumping systems. Beyond exposure to global perspectives on the role of technology/engineering in society, the exercise provided an opportunity for students to solidify and gain experience with their technical knowledge - an invaluable experience in an introductory fundamentals course. This experience therefore clearly illustrates the value of concurrently teaching technical and social aspects of Global Engineering - particularly through the use of case studies - as a means of engaging students and ensuring that the desired behavioural outcomes are achieved by the majority of engineering undergraduates.

\section{Conclusions}

The shift towards an outcomes-based accreditation process by the CEAB presents an ideal opportunity to create necessary change in the engineering education system. EWB's proposed four-year program outlines a potential means of integrating greater understanding of significant and critical issues into the current engineering curriculum, with the end goal of developing engineers that are better equipped to handle the increasingly complex challenges they are likely to face in engineering practice.

\section{Acknowledgements}

Engineers without Borders Canada would like to acknowledge the following individuals for their contributions to this work: Anna Akkerman and Dr. Annette Brendt (University of British Columbia) and Dan Lussier (University of Manitoba).

\section{References}

[1] Harris Interactive, "American perspectives on engineers and engineering: Poll conducted for the American Association of Engineering Societies," 2004.

[2] M. Knight and C. Cunningham, "Draw and engineer test (DAET): Development of a tool to investigate students' ideas about engineers and engineering," presented at the American Society for Engineering Education, Salt Lake City, 2004.

[3] C. Cunningham, et al., "Assessing elementary school students' conception of engineering and technology," presented at the American Society for Engineering Education, Portland, 2005.

[4] C. Cunningham, et al., "Elementary teachers' understandings of engineering and technology," presented at the American Society for Engineering Education, Chicago, 2006.

[5] A. D. Chan and J. FIshbein, "A global engineer for the global community," The Journal of Policy Engagement, vol. 1, pp. 4-9, 2009.

[6] CEAB, "Accreditation criteria and procedures 2008," Canadian Engineering Accreditation Board2008.

[7] A. Rugarcia, et al., "The Future of Engineering Education: I. A Vision for a New Century," Chemical Engineering Education, vol. 34, pp. 1625, 2000.

[8] C. Mechefske, et al., "Alumi/ae Surveys as Tools for Directing Change in Engineering Curriculum," presented at the 2nd International CDEN Conference, Kananaskis, 2005.

[9] Y.-L. Cheng, et al., "Interim Report of the Dean's Task Force on Globalization and Engineering," Faculty of Applied Science and Engineering, University of Toronto 2008 .

[10] R. M. Felder and R. Brent, "The ABC's of Engineering Education: ABET, Bloom's Taxonomy, Cooperative Learning, and so on," in American Society for Engineering Education Annual Conference and Exposition, Salt Lake City, 2004.

[11] J. M. Fishbein, "Developing Global Engineers: Incorporating International Development into the Engineering Curriculum," presented at the CSCE Forum on Professional Practice and Career Development, St. John's, Newfoundland and Labrador, 2009. 